Full-length article

\title{
Possible arrhythmiogenic mechanism produced by ibuprofen ${ }^{1}$
}

\author{
Zhi-fang YANG ${ }^{3}$, Hong-wei WANG ${ }^{3}$, Yan-qian $\mathrm{ZHENG}^{3}$, Yin $\mathrm{ZHANG}{ }^{3}$, Yuan-mou LIU, ${ }^{3} \mathrm{Ci}$-zhen $\mathrm{LI}^{2,3}$ \\ ${ }^{3}$ Department of Physiology, Medical School, Shanghai Jiaotong University, Shanghai 200025, China
}

\section{Key words}

ibuprofen; arrhythmias; action potentials; electrocardiogram

${ }^{1}$ Project supported by the Science Foundation
of Shanghai Education Committee (No
05BZ12) and the Science Foundation of
Shanghai Jiaotong University Medical
School (No 2005JY01).
${ }^{2}$ Correspondence to Dr Ci-zhen LI.
Phn 86-21-6467-2079.
Fax 86-21-5306-5329.
E-mail sljys@shsmu.edu.cn

Received 2007-05-15

Accepted 2007-10-29

doi: $10.1111 / \mathrm{j} .1745-7254.2008 .00754 . \mathrm{x}$

\begin{abstract}
Aim: The aim of the present study was to investigate the electrophysiological effect of ibuprofen on the cardiac action potentials (AP) and electrocardiograms (ECG), and to identify its arrhythmiogenic mechanism. Methods: The intracellular microelectrode recording technique was employed to record the fast- and slowresponse AP in guinea pig papillary muscles. The cardiac responses of ibuprofen were monitored by ECG, both in in vivo and in vitro studies. Results: The ECG recording revealed that ibuprofen could induce arrhythmias, both in vitro and in vivo. Fatal ventricular fibrillations are readily produced in in vitro experiments by ibuprofen. Our results show that ibuprofen could dose dependently shorten the duration of AP and the effective refractory period (ERP), and it could also decrease the maximum depolarization velocity of phase $0\left(V_{\max }\right)$ in both the fast- and slow-response AP. The duration of the QRS complex wave (QRS duration) in ECG was prolonged. Although the heart rate was depressed by ibuprofen, the corrected QT interval duration (QTc) decreased. Conclusion: Ibuprofen could inhibit cardiac $\mathrm{Na}^{+}$and $\mathrm{Ca}^{2+}$ channels as it slows $V_{\max }$ in both fast- and slowresponse AP. Furthermore, ibuprofen shortens the ERP and decreases the excitation propagation within the heart, which might provide a substrate for an arrhythmiogenic re-entry circuit. Taken together, we conclude that ibuprofen, when used improperly, may impose a potential hazard in inducing cardiac arrhythmias in patients with existing heart diseases.
\end{abstract}

\section{Introduction}

Ibuprofen (Fenbid) is a non-steroid anti-inflammatory drug (NSAID) often used to relieve fever and the symptoms of arthritis. Low doses of ibuprofen (200-1200 mg/d) are available over the counter in many countries as an analgesic. Its mechanism of action is believed to non-selectively inhibit both variants of cyclooxygenase (COX-1 and COX-2) and thus block prostaglandin synthesis. However, unlike aspirin, which also blocks both COX isoforms and prevents blood clotting, ibuprofen does not have antiplatelet effects and thus is not routinely used to prevent cardiac infarction.

The wide use of ibuprofen attributes to its lowest incidence in causing gastrointestinal dysfunction, a side-effect common to all non-selective COX inhibitors. Despite this advantage, the recent withdrawal of selective COX-2 inhibitor Vioxx (Merck \& Co, Inc, Whitehouse Station, New Jersey, USA). from the US market due to its cardiac toxic- ity brought all COX inhibitors under the spotlight and raised the question as to whether they could lead to elevated cardiovascular risk.

The initial study of potential cardiac toxicity in an ibuprofen cohort identified significantly higher rates of lifethreatening ventricular arrhythmias and cardiac arrest than those in the control naproxen cohort ${ }^{[1]}$. To date, with the extensive use of ibuprofen, the number of frequent ventricular premature beats, atrial fibrillation ${ }^{[2,3]}$, and other untoward cardiac reactions have been reported as increasing steadily ${ }^{[4-6]}$.

In spite of these clinical studies and case reports, very little work has been done to characterize the electrophysiological effects of ibuprofen on the animal heart. In the present study, we used isolated guinea pig hearts to identify the arrhythmiogenic effects of ibuprofen on the electrocardiogram (ECG); we examined its effects on the fast- and slowresponse cardiac action potentials (AP), and analyzed its 
dynamic process of combination and dissociation with the $\mathrm{Na}^{+}$channels. In conclusion, our results demonstrate for the first time that ibuprofen, a non-selective COX inhibitor, may induce cardiac arrhythmias by shortening the effective refractory period (ERP) and decreasing the excitation propagation.

\section{Materials and methods}

Solution preparation In total, $300 \mathrm{mg}$ ibuprofen was dissolved in $5 \mathrm{~mL}$ DMSO to make a stock solution of $60 \mathrm{mg} / \mathrm{mL}$. The stock solution would be further diluted to the designed concentrations in the Tyrode's solution. The normal Tyrode's solution for perfusing the cardiac ventricular cells of guinea pigs consisted of the following (in mmol/L): $137 \mathrm{NaCl}, 23$ $\mathrm{NaHCO}_{3}, 0.5 \mathrm{MgCl}_{2}, 5.4 \mathrm{KCl}, 1.8 \mathrm{CaCl}_{2}, 0.4 \mathrm{NaH}_{2} \mathrm{PO}_{4}$, and 10 glucose, $\mathrm{pH} 7.4 \pm 0.05$. The Tyrode's solution for the rabbit sinus node preparations consisted of the following $(\mathrm{mmol} / \mathrm{L})$ : $140 \mathrm{NaCl}, 1.0 \mathrm{MgCl}_{2}, 5.4 \mathrm{KCl}, 1.8 \mathrm{CaCl}_{2}, 5 \mathrm{HEPES}$, and 10 glucose, $\mathrm{pH} 7.4 \pm 0.05$. Both solutions were gas-saturated by $95 \% \mathrm{O}_{2}+5 \% \mathrm{CO}_{2}$ and $100 \% \mathrm{O}_{2}$, respectively.

ECG recording and measurement in vivo Guinea pigs of either sex (weighing approximately $500 \mathrm{~g}$ ) were anesthetized by an intraperitoneal injection (ip) of urethane $(20 \%$, $5 \mathrm{~mL} / \mathrm{kg}$ ). Needle electrodes, inserted subcutaneously, were used to record the ECG of standard limb lead II. The RR interval, QRS duration, QT interval, and heart rate variation (HRV) were measured, respectively. The corrected QT interval (QTc) was calculated with the Bazett formula $\left(\mathrm{QTc}=\mathrm{QT} \times \mathrm{RR}^{-1 / 2}\right)$ to reduce the influence of the fluctuation of the heart rate on the measurement of the QT interval. Different concentrations of ibuprofen were injected into the external jugular vein to evaluate its effects on the heart.

ECG recording in isolated heart The hearts of the anesthetized guinea pigs were quickly taken out of the chest and perfused with Langendorff perfusion set-up at a recorded pressure of $80 \mathrm{cmH}_{2} \mathrm{O}$. The temperature of the Tyrode's solution was maintained at $37 \pm 0.5^{\circ} \mathrm{C}$. Three platinum electrodes placed on the cardiac apex, right atrium, and aortic root were used to record the ECG. The signals were documented on computer using the PowerLab system (PowerLab ML135, ML 785, ADInstruments Castle Hill, NSW, Australia). The RR interval, QRS duration, QT interval, and QTc were analyzed.

Preparation of guinea pig papillary muscles Guinea pigs of either sex (weighing approximately $250 \sim 300 \mathrm{~g}$ ) were sacrificed by venesection under deep anesthesia with an injection of sodium pentobarbital $(35 \mathrm{mg} / \mathrm{kg}$, ip). The hearts were rapidly removed into the dissection chamber filled with the Tyrode's solution. The right ventricular papillary muscles were excised and pinned to the bottom of a recording chamber. The recording chamber was perfused with the Tyrode's solution at a constant rate of $3 \mathrm{~mL} / \mathrm{min}$ and maintained at a temperature of $37 \pm 0.5^{\circ} \mathrm{C}$.

Recording of fast-response AP Bipolar platinum electrodes were used to drive the preparations with rectangular current pulses at a stimulation frequency of $1 \mathrm{~Hz}$. Each pulse lasted for $0.1 \mathrm{~ms}$, with the amplitude approximately 1.5 times the threshold value. After 30 min stimulation, transmembrane AP were recorded by a conventional glass microelectrode, which was filled with $3 \mathrm{~mol} / \mathrm{L} \mathrm{KCl}$ and had a tip resistances of 15-20 M $\Omega$. The records were sampled and stored in the computer through the amplifier (MEZ8201, Nihon Kohden, Tokyo, Japan) and PowerLab interface (PowerLab ML785, ADInstruments, Australia $)^{[7]}$.

The calculated parameters for the fast-response AP included the resting potential (RP), AP amplitude (APA), maximum upstroke velocity of phase $0\left(V_{\max }\right)$, AP duration at $50 \%$ and $90 \%$ repolarization $\left(\mathrm{APD}_{50}\right.$ and $\left.\mathrm{APD}_{90}\right)$, and the ERP.

The preparations were driven by a series of 8 stimuli pulses at a frequency of $1 \mathrm{~Hz}$. Then an additional pulse was added following the eighth one. Adjusting the time interval between the eighth and the extra stimulation pulse, the minimum interval for the evoked AP by the extra stimulus would be calculated as the ERP.

Measurements of time constants for ibuprofen combined with and dissociated from fast $\mathrm{Na}^{+}$channels The preparations were stimulated at a frequency of 1,2 , and $3 \mathrm{~Hz}$, respectively. For each frequency, the stimulation would last until the $V_{\max }$ decreased gradually to a steady state, which could indicate the dynamics of the combination of ibuprofen with the fast $\mathrm{Na}^{+}$channels after repetitive activation of the channels. The first-order exponential decay equation was employed to fit the relationship between the decreased $V_{\max }$ values and the duration of the stimuli. The time constant $\left(\tau_{\text {on }}\right)$ thus obtained is the index of the combination dynamics of ibuprofen with the fast $\mathrm{Na}^{+}$channels. Origin 6 software (Microcal Software, Northampton, MA, USA) was used to analyze the data.

With a similar protocol, the preparations were activated for $30 \mathrm{~s}$ at a frequency of 1,2 , or $3 \mathrm{~Hz}$, respectively. After the $V_{\max }$ for each frequency decreased to a steady state, a various delayed supra-threshold stimulus was added to invoke an additional AP, and the $V_{\max }$ of the first evoked AP with various delays were measured. As the drug needs time to dissociate from the channels, it was found that the longer the retardation time for evocation, the greater the $V_{\max }$ of the evoked AP. The relationship of the $V_{\max }$ value and the retardation time was fitted by the first-order exponential decay 
equation. The time constant $\left(\tau_{\text {off }}\right)$ would represent the dissociation index of ibuprofen from the $\mathrm{Na}^{+}$channels.

Recording of slow-response AP of guinea pig papillary muscles When the preparations were perfused with the Tyrode's solution containing $27 \mathrm{mmol} / \mathrm{L} \mathrm{KCl}$, the resting potential would gradually change to approximately $-45 \mathrm{mV}$. The $\mathrm{Na}^{+}$channels would be inactivated at this membrane level. After $0.4 \mathrm{mg} / \mathrm{L}$ isoprenaline was added into the Tyrode's solution and a stronger stimulus was employed to the preparation, the slow-response AP, which were evoked by the slow inward current of the $\mathrm{Ca}^{2+}$ rather than the $\mathrm{Na}^{+}$ channels, could be initiated ${ }^{[8]}$.

Spontaneous AP of rabbit sinus node cells Adult rabbits of either sex were anesthetized by injection of sodium pentobarbital $(1 \%, 3 \mathrm{~mL} / \mathrm{kg})$. The hearts were removed to a chamber containing the Tyrode's solution. The sinus nodes were excised from the heart and pinned to the bottom of the recording chamber, which was perfused with the special Tyrode's solution for sinus nodes. An intracellular microelectrode (containing $3 \mathrm{~mol} / \mathrm{L} \mathrm{KCl}$ with a tip resistance of 25 $\mathrm{M} \Omega$ ) was employed to record the spontaneous AP of the sinus node cells. The parameters of AP were sampled with the same method as described in fast-response AP. The spontaneous beating rate, APA, APD, $V_{\max }$ and spontaneous depolarization rate of phase 4 (SDR) were calculated, respectively.

Statistical analysis All of the data were sampled by Chart
Table 1. Dose-dependent effects of ibuprofen on ECG of guinea pigs in vivo. $n=6$. Mean $\pm \mathrm{SD} .{ }^{\mathrm{b}} P<0.05,{ }^{\mathrm{c}} P<0.01$ vs control. $\mathrm{QTc}=\mathrm{QT} \times \mathrm{RR}^{-1 / 2}$.

\begin{tabular}{cllll}
\hline Ibuprofen (mg/kg) & QRS (ms) & RR (ms) & QT (ms) & QTc \\
\hline & & & & \\
Control & $13 \pm 1$ & $230 \pm 4$ & $130 \pm 4$ & $271 \pm 4$ \\
2 & $14 \pm 2$ & $237 \pm 5$ & $128 \pm 5$ & $263 \pm 5$ \\
5 & $15 \pm 2$ & $247 \pm 5^{\mathrm{b}}$ & $125 \pm 4$ & $252 \pm 5^{\mathrm{c}}$ \\
10 & $17 \pm 2^{\mathrm{b}}$ & $256 \pm 6^{\mathrm{b}}$ & $124 \pm 3^{\mathrm{b}}$ & $245 \pm 5^{\mathrm{c}}$ \\
20 & $19 \pm 2^{\mathrm{b}}$ & $260 \pm 5^{\mathrm{c}}$ & $122 \pm 3^{\mathrm{b}}$ & $239 \pm 4^{\mathrm{c}}$ \\
25 & $20 \pm 1^{\mathrm{c}}$ & $268 \pm 5^{\mathrm{c}}$ & $119 \pm 3^{\mathrm{c}}$ & $230 \pm 4^{\mathrm{c}}$ \\
\hline
\end{tabular}

5 software (ADInstruments, Australia). Origin 6 was used for the statistical analysis. The results were expressed as mean \pm SD. Statistical significance was determined by Student's $t$-test for paired data. $P<0.05$ was considered statistically significant.

\section{Results}

ECG from anesthetized guinea pigs ECG of standard limb lead II from urethane-anesthetized guinea pigs were recorded. Every $10 \mathrm{~min}$, ibuprofen was consecutively injected into the external jugular vein to reach a concentration of 2, 5, 10, 20, $25 \mathrm{mg} / \mathrm{kg}$, respectively (Table 1; Figure 1A). After $25 \mathrm{mg} / \mathrm{kg}$ ibuprofen, ECG exhibited a marked increase

A
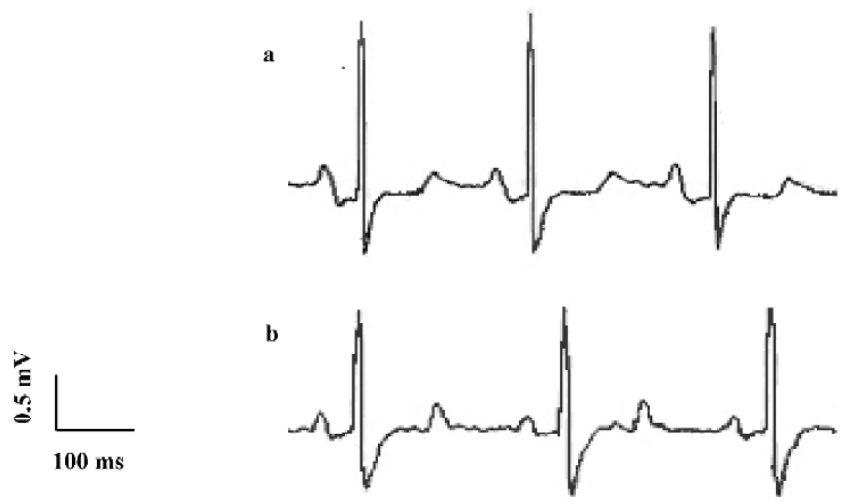

B

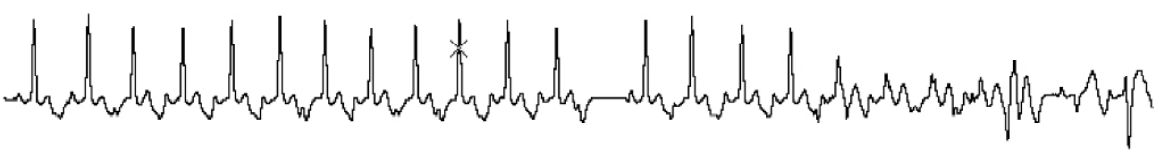

Figure 1. Ibuprofen affected ECG from anesthetized guinea pigs and induced ventricular fibrillation. (A) effect of ibuprofen on ECG from anesthetized guinea pigs. (a) control; (b) $10 \mathrm{~min}$ after $25 \mathrm{mg} / \mathrm{kg}$ ibuprofen vein injection. (B) ibuprofen $(25 \mathrm{mg} / \mathrm{kg}$ ) induced ventricular fibrillation on ECG of guinea pigs. 
$\mathbf{A}$
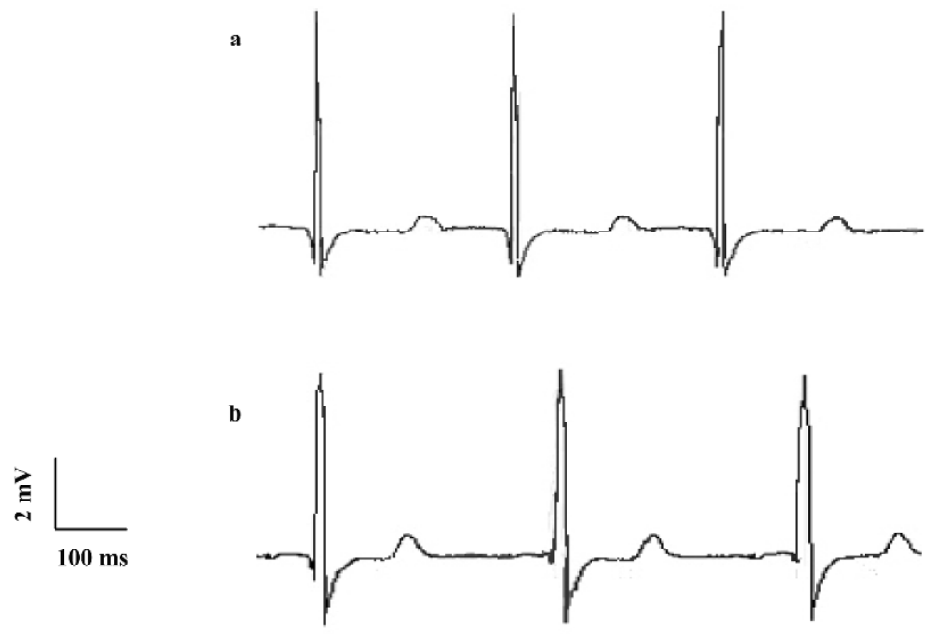

B

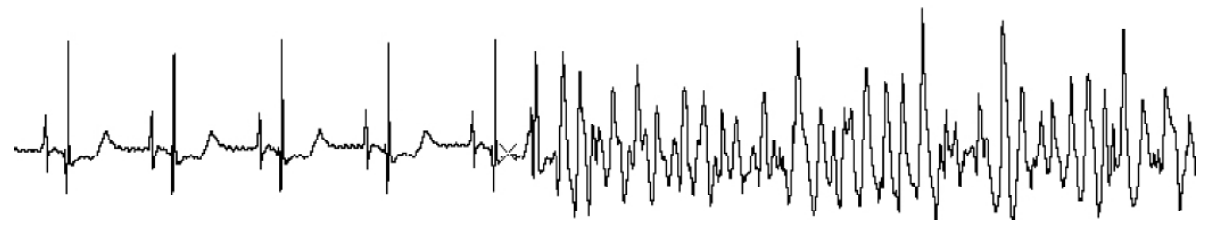

Figure 2. Ibuprofen affected ECG in isolated hearts and induced ventricular fibrillation. (A) Effects of ibuprofen on ECG in the isolated guinea pig hearts. (a) control; (b) $10 \mathrm{~min}$ after $40 \mathrm{mg} / \mathrm{L}$ ibuprofen. (B) ibuprofen $(40 \mathrm{mg} / \mathrm{L})$ induced ventricular fibrillation on ECG of the isolated guinea pig hearts.

of the QRS duration (from $13 \pm 1 \mathrm{~ms}$ to $20 \pm 1 \mathrm{~ms} v$ s control) and RR intervals (from $230 \pm 4 \mathrm{~ms}$ to $268 \pm 5 \mathrm{~ms}$ ) with percentage changes of $53.8 \%$ and $16.5 \%$, respectively. However, the QTc decreased from $271 \pm 4 \mathrm{~ms}$ to $230 \pm 4 \mathrm{~ms}$ by a significant change of $15.1 \%$. A HRV analysis showed that the main parameters of HRV (including the standard deviation of the RR intervals (SDNN), the low frequency power density component (LF), the high frequency power density component (HF), LF/HF ratio (LF/HF)] were not changed significantly after an intravenous injection of ibuprofen. In order to exclude the possible effect from DMSO, we performed the 5 control experiments, with an intravenous injection of DMSO $(417 \mu \mathrm{L} / \mathrm{kg}$ ) alone, $50 \mathrm{~min}$ after the injection of DMSO, QRS (ms), RR (ms), QT (ms), and QTc were measured. These did not change significantly on the ECG of the guinea pigs: $13.7 \pm 0.7,213 \pm 7,119 \pm 11$, and $259 \pm 14$ to $13.8 \pm 0.6,206 \pm 9$, $123 \pm 13$, and $272 \pm 18$, respectively. The results indicate that DMSO has no significant effect on the ECG of guinea pigs in vivo $(P>0.05)$.

Premature contractions and ventricular fibrillations occurred in some animal experiments. Ventricular fibrillations occurred in 2 of 6 guinea pigs, which later recovered with an injection of a low dosage of ibuprofen (5 or 10 $\mathrm{mg} / \mathrm{kg}$ ); $25 \mathrm{mg} / \mathrm{kg}$ ibuprofen induced fatal ventricular fibrillations in another two guinea pigs (Figure 1B).

Effects of ibuprofen on ECG in isolated hearts The isolated guinea pig hearts were perfused with the Tyrode's solution. Every $10 \mathrm{~min}$, the heart was consecutively perfused with ibuprofen at concentrations of 5, 10, 20, 40, and 80 $\mathrm{mg} / \mathrm{L}$ respectively, while the ECG was recorded. The results in Table 2 show that like the in vivo experiments, ibuprofen could prolong the duration of the QRS wave and the RR interval (Figure 2A). Although ibuprofen decreased the heart rate, it shortened the QT interval, especially the QTc. When the hearts were exposed to $20 \mathrm{mg} / \mathrm{L}$ ibuprofen, some ECG showed arrhythmias (especially ventricular premature contractions), but most disappeared within $30 \mathrm{~min}$. With $40 \mathrm{mg} / \mathrm{L}$ ibuprofen, ventricular fibrillations occurred in 3 of 7 experiments and recovered later after washing out with the control Tyrode's solution. In another experiment with a higher concentration of ibuprofen $(80 \mathrm{mg} / \mathrm{L}), 2$ hearts stopped beating after sustained ventricular fibrillations (Figure 2B).

Effects of ibuprofen on fast-response AP of guinea pig papillary muscles In order to get a stable recording of fastresponse AP, the papillary muscles of the guinea pigs were 
Table2. Effects of ibuprofen on ECG in isolated hearts. ${ }^{\mathrm{b}} P<0.05,{ }^{\mathrm{c}} P<0.01$ vs control. $n=7$. Mean $\pm \mathrm{SD}$. QTc $=\mathrm{QT} \times \mathrm{RR}^{-1 / 2}$.

\begin{tabular}{|c|c|c|c|c|c|}
\hline Ibuprofen (mg/L) & QRS (s) & $\mathrm{RR}(\mathrm{s})$ & Heart rate $\left(\mathrm{min}^{-1}\right)$ & QT (s) & QTc (s) \\
\hline Control & $0.013 \pm 0.001$ & $0.286 \pm 0.006$ & $210 \pm 4$ & $0.197 \pm 0.005$ & $0.368 \pm 0.008$ \\
\hline 5 & $0.015 \pm 0.002$ & $0.298 \pm 0.007$ & $201 \pm 5$ & $0.195 \pm 0.005$ & $0.357 \pm 0.007$ \\
\hline 10 & $0.015 \pm 0.001$ & $0.321 \pm 0.010^{\mathrm{b}}$ & $187 \pm 4^{\mathrm{b}}$ & $0.195 \pm 0.007$ & $0.344 \pm 0.007^{\mathrm{b}}$ \\
\hline 20 & $0.016 \pm 0.001^{\mathrm{b}}$ & $0.334 \pm 0.009^{c}$ & $180 \pm 4^{\mathrm{c}}$ & $0.193 \pm 0.006$ & $0.334 \pm 0.005^{b}$ \\
\hline 40 & $0.020 \pm 0.002^{\mathrm{c}}$ & $0.345 \pm 0.008^{c}$ & $174 \pm 4^{\mathrm{c}}$ & $0.191 \pm 0.005$ & $0.325 \pm 0.005^{\mathrm{c}}$ \\
\hline 80 & $0.022 \pm 0.002^{\mathrm{c}}$ & $0.355 \pm 0.010^{\mathrm{c}}$ & $169 \pm 3^{c}$ & $0.184 \pm 0.004^{\mathrm{b}}$ & $0.309 \pm 0.006^{\mathrm{c}}$ \\
\hline Wash-out & $0.015 \pm 0.002$ & $0.327 \pm 0.09^{b}$ & $183 \pm 5^{\mathrm{b}}$ & $0.193 \pm 0.005$ & $0.338 \pm 0.006^{\mathrm{b}}$ \\
\hline
\end{tabular}

stimulated at a frequency of $1 \mathrm{~Hz}$ for approximately $30 \mathrm{~min}$. Then the preparations were perfused consecutively with 10 , 20, 40, and $80 \mathrm{mg} / \mathrm{L}$ Tyrode's solution containing ibuprofen. Each performance lasted for $10 \mathrm{~min}$. The results are shown in Figure 3 and Table 3. Ibuprofen can dose dependently shorten the $\mathrm{APD}_{50}$ by $30.9 \%$ (from $165.8 \pm 12.5 \mathrm{~ms}$ to $114.5 \pm 6.4 \mathrm{~ms}$ ), $\mathrm{APD}_{90}$ by $25.6 \%$ (from $203.4 \pm 14.3 \mathrm{~ms}$ to $151.3 \pm 9.8 \mathrm{~ms}$ ), $V_{\text {max }}$ by $14.7 \%$ (from $225.4 \pm 11.3 \mathrm{~V} / \mathrm{s}$ to $192.2 \pm 9.6 \mathrm{~V} / \mathrm{s}$ ), and ERP by

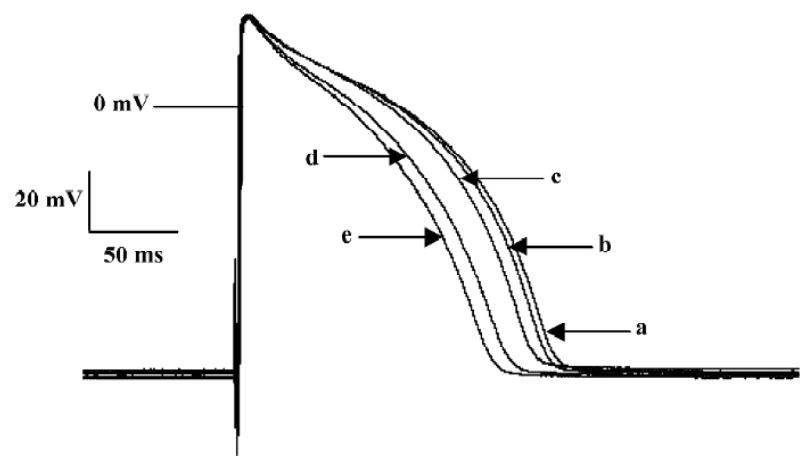

Figure 3. Dose-dependent effect of ibuprofen on AP from papillary muscles of guinea pigs. (a) control; (b) $10 \mathrm{~min}$ after $10 \mathrm{mg} / \mathrm{L}$ ibuprofen; (c) $10 \mathrm{~min}$ after $20 \mathrm{mg} / \mathrm{L}$ ibuprofen; (d) $10 \mathrm{~min}$ after $40 \mathrm{mg} / \mathrm{L}$ ibuprofen; (e) 10 min after $80 \mathrm{mg} / \mathrm{L}$ ibuprofen.
$24.3 \%$ (from $186.6 \pm 11.2 \mathrm{~ms}$ to $141.3 \pm 8.3 \mathrm{~ms}$ ), respectively. No obvious influence of ibuprofen on RP and APA were observed. When the preparations were washed out with the control Tyrode's solution for $30 \mathrm{~min}$, all the changes could obviously be reversed.

Dynamics of ibuprofen combined with and dissociated from the fast $\mathrm{Na}^{+}$channels Ibuprofen can inhibit the $\mathrm{Na}^{+}$ channels; the $V_{\max }$ of the fast-response AP is dramatically depressed by ibuprofen (Table 3 ). In a series of stimuli with frequencies lasting approximately $30 \mathrm{~s}$, the value of the $V_{\max }$ will decrease from the first evoked response, then gradually diminish into a steady state (Figure 4). With the different concentrations of ibuprofen (20 and $40 \mathrm{mg} / \mathrm{L}$ for $15 \mathrm{~min}$, shown in the lower two rows of the Figure 4), the stimulation rate was increased from 1 to 2 or $3 \mathrm{~Hz}$ for more than $30 \mathrm{~s}$ for each frequency. The combination time constant $\left(\tau_{\text {on }}\right)$ of ibuprofen with the $\mathrm{Na}^{+}$channels was calculated and shown in Table 4. Our results show that the higher the concentration of ibuprofen used, the shorter the time constant of $\tau_{\text {on }}$; the higher the stimulus frequency, the shorter the time constant of $\tau_{\text {on }}$ (Figure 4; Table 4). These results indicate that ibuprofen is much easier to combine with the $\mathrm{Na}^{+}$ channels at a high stimulation frequency than that at a

Table 3. Dose-dependent effects of ibuprofen on fast-response AP from papillary muscles of guinea pigs. ${ }^{\mathrm{b}} P<0.05,{ }^{\mathrm{c}} P<0.01 v s$ control. $n=6$. Mean \pm SD.

\begin{tabular}{|c|c|c|c|c|c|c|}
\hline Ibuprofen (mg/L) & $\mathrm{RP}(\mathrm{mV})$ & APA $(m V)$ & $\mathrm{APD}_{90}(\mathrm{~ms})$ & $\mathrm{APD}_{50}(\mathrm{~ms})$ & $V_{\max }(\mathrm{V} / \mathrm{s})$ & $\mathrm{ERP}(\mathrm{ms})$ \\
\hline Control & $-90.1 \pm 4.3$ & $125.2 \pm 3.8$ & $203.4 \pm 14.3$ & $165.8 \pm 12.5$ & $225.4 \pm 11.3$ & $186.6 \pm 11.2$ \\
\hline 5 & $-89.2 \pm 3.5$ & $125.0 \pm 4.1$ & $201.5 \pm 14.1$ & $164.4 \pm 10.3$ & $223.5 \pm 10.5$ & $185.3 \pm 10.4$ \\
\hline 10 & $-89.7 \pm 3.9$ & $124.6 \pm 4.7$ & $198.2 \pm 13.7$ & $160.3 \pm 10.7$ & $222.1 \pm 10.7$ & $181.9 \pm 9.5$ \\
\hline 20 & $-89.5 \pm 3.6$ & $122.6 \pm 3.8$ & $176.8 \pm 12.0^{\mathrm{b}}$ & $133.3 \pm 8.1^{\mathrm{c}}$ & $220.3 \pm 10.8$ & $166.8 \pm 9.6^{\mathrm{b}}$ \\
\hline 40 & $-89.9 \pm 3.4$ & $123.4 \pm 4.3$ & $162.3 \pm 11.5^{\mathrm{c}}$ & $122.7 \pm 7.7^{\mathrm{c}}$ & $201.4 \pm 9.3^{\mathrm{b}}$ & $153.4 \pm 8.4^{\mathrm{c}}$ \\
\hline 80 & $-87.8 \pm 3.5$ & $121.0 \pm 3.9$ & $151.3 \pm 9.8^{c}$ & $114.5 \pm 6.4^{c}$ & $192.2 \pm 9.6^{c}$ & $141.3 \pm 8.3^{\mathrm{c}}$ \\
\hline Wash-out & $-89.7 \pm 2.9$ & $122.5 \pm 3.5$ & $186.4 \pm 10.2$ & $143.2 \pm 9.6$ & $216.6 \pm 9.5$ & $173.5 \pm 10.1$ \\
\hline
\end{tabular}



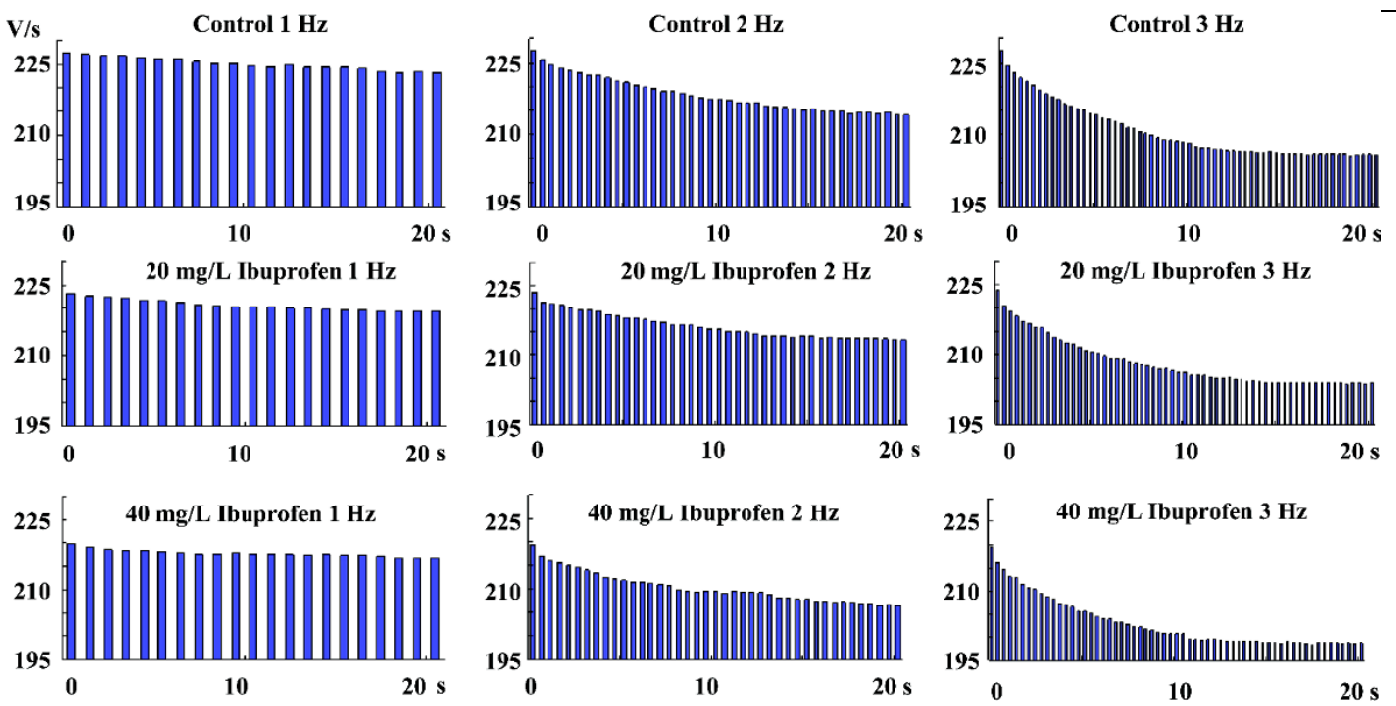

Figure 4. Effects of ibuprofen on the combination time constant with the fast sodium channel of guinea pig papillary muscles. Ordinate represents the $V_{\max }$ of the fast response AP (V/s). Abscissa indicates the time of a series of stimuli with certain frequencies.

Table 4. Time constants for ibuprofen combined with and dissociated from sodium channel. ${ }^{\mathrm{b}} P<0.05,{ }^{\mathrm{c}} P<0.01$ vs control. $n=5$. Mean \pm SD.

\begin{tabular}{ccccc}
\hline $\begin{array}{c}\text { Frequency of } \\
\text { stimulation }(\mathrm{mg} / \mathrm{L})\end{array}$ & \multicolumn{2}{c}{$2 \mathrm{~Hz}$} & $\begin{array}{l}3 \mathrm{~Hz} \\
\text { (Time constants) }\end{array}$ & \\
& & & & \\
& & & & \\
& $\tau_{\text {on }}(\mathrm{s})$ & $\tau_{\text {off }}(\mathrm{s})$ & $\tau_{\text {on }}(\mathrm{s})$ & $\tau_{\text {off }}(\mathrm{s})$ \\
Control & $8.9 \pm 0.8$ & $10.3 \pm 1.1$ & $5.6 \pm 0.3$ & $7.5 \pm 0.8$ \\
20 & $8.1 \pm 0.6$ & $8.9 \pm 0.9$ & $5.2 \pm 0.2$ & $6.3 \pm 0.6^{\mathrm{b}}$ \\
40 & $7.4 \pm 0.6^{\mathrm{b}}$ & $8.2 \pm 0.7^{\mathrm{b}}$ & $4.8 \pm 0.2^{\mathrm{c}}$ & $5.7 \pm 0.5^{\mathrm{c}}$ \\
& & & & \\
\hline
\end{tabular}

$\tau_{\text {on }}$, combination time constant; $\tau_{\text {off }}$, dissociation time constant.

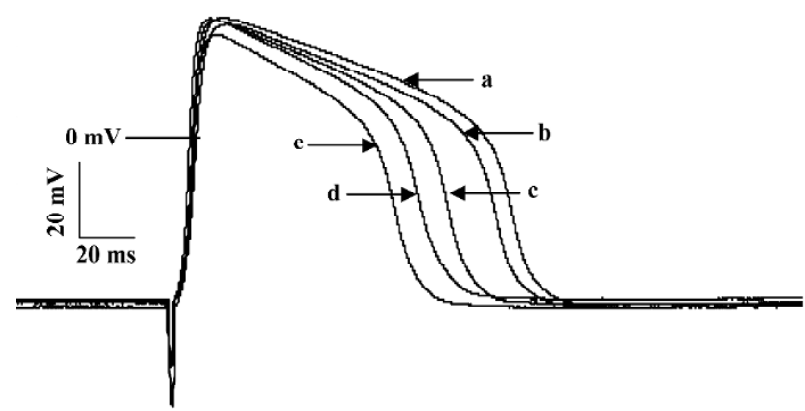

Figure 5. Dose-dependent effects of ibuprofen on slow-response AP of papillary muscles of guinea pigs. (a) control; (b)10 min after $10 \mathrm{mg} / \mathrm{L}$ ibuprofen; (c) $10 \mathrm{~min}$ after $20 \mathrm{mg} / \mathrm{L}$ ibuprofen; (d) $10 \mathrm{~min}$ after $40 \mathrm{mg} / \mathrm{L}$ ibuprofen; (e) $10 \mathrm{~min}$ after $80 \mathrm{mg} / \mathrm{L}$ ibuprofen.

lower one.

The dissociation time constant is longer than that of the combination ones for each different stimulation frequency (Table 4). As the ibuprofen concentration or the stimulation frequency increased, the dissociation course became much faster.

Effects of ibuprofen on slow-response AP After the slowresponse AP of papillary muscles were recorded, the preparation were consecutively perfused with $5,10,20,40$, and 80 $\mathrm{mg} / \mathrm{L}$ ibuprofen contained in Tyrode's solution at an interval of 10 min for each concentration, as shown in Figure 5. The results in Table 5 show that ibuprofen $(80 \mathrm{mg} / \mathrm{L})$ could attenuate $\mathrm{APD}_{50}$ (from $118.6 \mathrm{~ms}$ to $85.3 \mathrm{~ms}$ ), $\mathrm{APD}_{90}$ (from $131.9 \mathrm{~ms}$ to $98.5 \mathrm{~ms}$ ), $V_{\max }$ (from $31.3 \mathrm{~V} / \mathrm{s}$ to $10.2 \mathrm{~V} / \mathrm{s}$ ), and ERP (from $226.2 \mathrm{~ms}$ to $154.6 \mathrm{~ms}$ ), with percentage changes of $28.1 \%, 25.3 \%, 67.4 \%$, and $31.7 \%$, respectively. No substantial alterations were observed regarding RP and APA.

Effects of ibuprofen on spontaneous AP The spontaneous AP were recorded in rabbit sinus node preparations. The sinus node were exposed to 5, 10, 20, 40, and $80 \mathrm{mg} / \mathrm{L}$ ibuprofen consecutively. The results in Table 6 demonstrate that $80 \mathrm{mg} / \mathrm{L}$ ibuprofen decreases the $V_{\max }$ by $40.2 \%$, the beating rate by $12.4 \%$, and the SDR by $38.5 \%$, respectively. These effects of ibuprofen are dose dependent and reversible after washing out with control Tyrode's solution. Figure 6 shows the effects of ibuprofen on the spontaneous AP of sinus nodes.

\section{Discussion}

NSAIDs are chemicals that present analgesic and antiinflammatory effects, and most of them, including aspirin and ibuprofen, act as non-selective inhibitors of prostaglan- 
Table 5. Dose-dependent effects of ibuprofen on slow-response AP of guinea pig papillary muscle. ${ }^{\mathrm{b}} P<0.05,{ }^{\mathrm{c}} P<0.01 v s$ control, $n=7$, mean \pm SD.

\begin{tabular}{|c|c|c|c|c|c|c|}
\hline Ibuprofen (mg/L) & $\mathrm{RP}(\mathrm{mV})$ & $\operatorname{APA}(\mathrm{mV})$ & $\mathrm{APD}_{50}(\mathrm{~ms})$ & $\mathrm{APD}_{90}(\mathrm{~ms})$ & $V_{\max }\left(\mathrm{V} \cdot \mathrm{s}^{-1}\right)$ & $\mathrm{ERP}(\mathrm{ms})$ \\
\hline Control & $-45.8 \pm 2.3$ & $78.3 \pm 4.1$ & $118.6 \pm 9.9$ & $131.9 \pm 12.1$ & $31.3 \pm 3.4$ & $226.2 \pm 15.1$ \\
\hline 5 & $-45.7 \pm 2.6$ & $77.5 \pm 3.2$ & $116.2 \pm 9.5$ & $127.3 \pm 11.8$ & $30.8 \pm 3.1$ & $223.4 \pm 15.3$ \\
\hline 10 & $-46.1 \pm 3.3$ & $76.0 \pm 3.7$ & $101.4 \pm 8.2$ & $114.8 \pm 10.0$ & $25.5 \pm 2.9^{b}$ & $202.7 \pm 13.6$ \\
\hline 20 & $-45.6 \pm 2.5^{\prime}$ & $75.8 \pm 3.4$ & $97 \pm 6.1^{\mathrm{b}}$ & $109.6 \pm 9.4^{b}$ & $19.9 \pm 2.7^{c}$ & $186.3 \pm 12.9^{b}$ \\
\hline 40 & $-45.5 \pm 2.8$ & $76.9 \pm 4.4$ & $90.5 \pm 5.4^{c}$ & $103.4 \pm 8.2^{\mathrm{c}}$ & $14.7 \pm 2.2^{\mathrm{c}}$ & $172.1 \pm 10.3^{c}$ \\
\hline 80 & $-44.7 \pm 3.8$ & $73.6 \pm 3.3$ & $85.3 \pm 7.3^{c}$ & $98.5 \pm 9.7^{\mathrm{c}}$ & $10.2 \pm 2.0^{\mathrm{c}}$ & $154.6 \pm 10.9^{c}$ \\
\hline Wash-out & $-45.4 \pm 2.9$ & $77.5 \pm 3.6$ & $114.5 \pm 13.9$ & $125.8 \pm 12.9$ & $25.6 \pm 2.7^{b}$ & $199.4 \pm 11.5^{b}$ \\
\hline
\end{tabular}

Table 6. Dose-dependent effects of ibuprofen on spontaneous AP of rabbit sinus nodes. ${ }^{\mathrm{b}} P<0.05,{ }^{\mathrm{c}} P<0.01$ vs control. $n=6$. Mean \pm SD.

\begin{tabular}{cllll}
\hline $\begin{array}{c}\text { Ibuprofen } \\
(\mathrm{mg} / \mathrm{L})\end{array}$ & $\begin{array}{c}\text { Heart rate } \\
(\text { beat } / \mathrm{min})\end{array}$ & $\begin{array}{c}\mathrm{SDR} \\
(\mathrm{mV} / \mathrm{s})\end{array}$ & $\begin{array}{c}\text { APA } \\
(\mathrm{mV})\end{array}$ & $\begin{array}{c}V_{\max } \\
(\mathrm{V} / \mathrm{s})\end{array}$ \\
\hline & & & & \\
Control & $92.3 \pm 5.8$ & $31.7 \pm 2.9$ & $72.6 \pm 4.4$ & $9.7 \pm 1.1$ \\
5 & $91.0 \pm 6.1$ & $30.3 \pm 2.5$ & $72.3 \pm 4.9$ & $9.3 \pm 1.0$ \\
10 & $89.5 \pm 6.6$ & $28.4 \pm 2.1$ & $70.8 \pm 4.7$ & $8.7 \pm 0.9$ \\
20 & $85.2 \pm 5.3$ & $25.6 \pm 1.5^{\mathrm{b}}$ & $69.5 \pm 5.2$ & $7.4 \pm 0.6^{\mathrm{b}}$ \\
40 & $82.8 \pm 5.7^{\mathrm{b}}$ & $22.3 \pm 1.6^{\mathrm{c}}$ & $68.3 \pm 4.7$ & $6.6 \pm 0.5^{\mathrm{b}}$ \\
80 & $80.9 \pm 5.2^{\mathrm{b}}$ & $19.5 \pm 1.3^{\mathrm{c}}$ & $67.4 \pm 4.1$ & $5.8 \pm 0.5^{\mathrm{c}}$ \\
Wash-out & $87.6 \pm 6.4$ & $27.2 \pm 2.6$ & $70.2 \pm 5.3$ & $8.5 \pm 0.8$ \\
\hline
\end{tabular}

din synthesis enzymes COX-1 and COX-2. By contrast, selective COX-2 inhibitors specifically block the production of the type of prostaglandins responsible for pain and inflammation. Hence, it was believed that selective COX-2 antagonists had more curative and fewer side-effects.

Ever since Merck withdrew its COX-2 antagonist Vioxx, a $\$ 2.5$ billion/year sales blockbuster, because of high cardiovascular risk, the safety concerns over all COX inhibitors have received wide attention across the entire pharmaceutical industry. The cardiotoxicity of COX-2 inhibitors has been considered to result from the suppression of prostaglandin synthesis in endothelial cells ${ }^{[9,10]}$. Reduced prostaglandin in blood vessels would prevent vasorelaxation and facilitate clot formation, and thus predispose patients with existing heart diseases higher chances of myocardial infarction ${ }^{[11,12]}$. Although a similar association was obtained in other large population studies, in which high doses of traditional nonselective COX inhibitors were used to compare with placebo controls ${ }^{[13-15]}$, the underlying mechanisms remain unknown.

In the present research, we studied the effects of ibuprofen on fast- and slow-response AP in guinea pig papillary muscles, on the spontaneous AP of rabbit sinus nodes, and the ECG of guinea pigs in order to elucidate its cardiac sideeffects. During both the in vitro and in vivo ECG recording, ibuprofen prolonged the duration of the QRS complex wave and inversely shortened the QTc. The duration of QRS represents the propagating velocity of excitation in the heart. We also found that at a low dosage of ibuprofen (10-20 mg/L), certain types of arrhythmias, such as premature ventricular contraction and short duration ventricular fibrillation, could occur, and these events were reversible after ibuprofen was washed out with control solution. At a high dosage of ibuprofen (40-80 mg/L), 2 of 8 hearts stopped beating because of long-lasting ventricular fibrillations. These observations suggest that ibuprofen exhibit detrimental effects on heart function.

Next, we investigated the effect of ibuprofen at the cellular level, that is, its influence on cardiac AP. Figures 3 and 5 demonstrate that ibuprofen could dose dependently suppress $V_{\max }$ in fast-response AP by $14.7 \%$, and decrease the $V_{\max }$ of slow-response AP by $67.4 \%$, suggesting that ibuprofen is able to block the fast $\mathrm{Na}^{+}$channel and the slow $\mathrm{Ca}^{2+}$ channel. Tables 3 and 5 further show that ibuprofen could not only decrease the fast and slow AP duration $\left(\mathrm{APD}_{50}\right)$ by $30.9 \%$ and $28.1 \%$, but also shorten the effective refractory periods by $24.3 \%$ and $31.7 \%$, respectively. In sinus node cells, we found that ibuprofen decreased the SDR, slowing the heart rate in 6 experiments.

Interestingly, our data also imply that ibuprofen may directly interact with the cardiac $\mathrm{Na}^{+}$channel. The changes of the association and dissociation time constants ( $\tau_{\text {on }}$ and $\left.\tau_{\text {off }}\right)$ in Figure 4 provide evidence that the drug molecule may interact and inhibit the $\mathrm{Na}^{+}$channel quicker as its concentration increase or during fast heart rates. The results presented in Tables 2, 3, 5, and 6 indicate that these alterations 


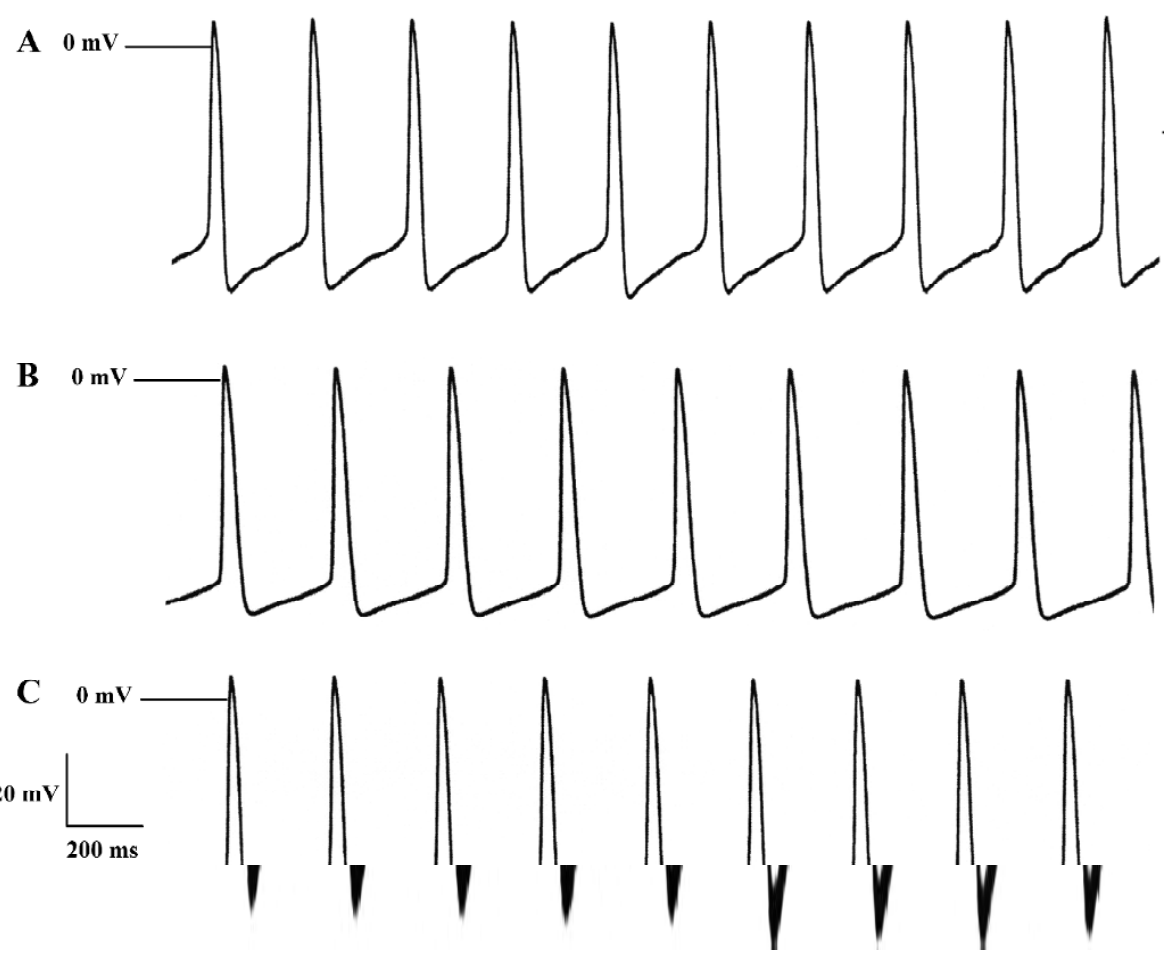

Figure 6. Effects of ibuprofen on spontaneous AP of rabbit sinus nodes. (A) control; (B) $10 \mathrm{~min}$ after $80 \mathrm{mg} / \mathrm{L}$ ibuprofen; (C) washout.

could not be reversed completely to the baseline after wash out. We believe that this effect may be induced by the prolonged exposure to high concentrations of ibuprofen during recording, lack of solvent DMSO in the wash solution, or a higher affinity of ibuprofen to the $\mathrm{Na}^{+}$channel $\left(\tau_{\text {on }<} \tau_{\text {off }}\right)$, as illustrated in Table 4.

It might be speculated that ibuprofen could dose dependently suppress the $\mathrm{Na}^{+}$and $\mathrm{Ca}^{2+}$ channels, and decrease the excitation spreading within the heart. The slower conduction is displayed on the ECG by the prolongation of the QRS wave. The decrease of the APD in AP recording could explain the shortening of the QTc produced by ibuprofen on ECG.

It is well known that slow conduction, shortening of the refractory period, and unidirectional blocking are the 3 important preconditions for re-entry that results in fibrillations in the heart. Since ibuprofen could slow conduction and decrease the refractory period, it might therefore lead to arrhythmias in clinical practice.

On the contrary, some reports indicate that NSAIDs, such as salicylic acid (SA), can reduce ventricular dysfunction and arrhythmias ${ }^{[16-18]}$. The investigators proposed that ibuprofen could prevent the atrial fibrillation mediated by inflammation, and SA could trap the hydroxyl radicals to reduce postischemic ventricular arrhythmias. Yet, those ex- periments were conducted on patients with heart diseases or on isolated ischemic hearts. By contrast, our study was performed on healthy animals and heart preparations. Nevertheless, they found that only low concentration of SA $(0.5$ and $1.0 \mathrm{mmol} / \mathrm{L})$ prevented the risk of arrhythmias; at higher concentrations, the drugs lost their protective functions in the trials. It is known that anti-arrhythmia drugs are 2-edged swords; they can be used to treat one type of arrhythmia, but at the same time become pro-arrhythmic to another. It is also known that their arrhythmiogenic effects depend on, to some extent, the pathophysiological conditions of the diseased heart. Taken together, the results presented in this paper suggest that patients with existing heart diseases should cautiously take NSAIDs, unless they are under close observation of the side-effects.

\section{References}

1 Pratt CM, Hertz RP, Ellis BE, Crowell SP, Louv W, Moyé L. Risk of developing life-threatening ventricular arrhythmia associated with tefenadine in comparison with over-the-counter antihistamines, ibuprofen and clemastine. Am J Cardiol 1994; 15: $346-52$.

2 Wu ZG, Zhou XL, Shu CM. Arrhythmia induced by the use of ibuprofen. Chin Foreign Med J 2005; 3: 88-9

3 Shi YL, Wang YZ, Zhao XL. One case of atrial fibrillation induced by ibuprofen. J Med Theor Prac 2004; 17: 447. 
4 Huerta C, Varas-Lorenzo C, Castellsague J, Garcia Rodriguez LA. Non-steroidal anti-inflammatory drugs and risk of first hospital admission for heart failure in the general population. Heart 2006; 92: 1610-5.

5 Hudson M, Richard H, Pilote L. Differences in outcomes of patients with congestive heart failure prescribed celecoxib, rofecoxib, or non-steroidal anti-inflammatory drugs: population based study. Br Med J 2005; 300: 1370-3.

6 Bresalier RS, Sandler RS, Quan H, Bolognese JA, Oxenius B, Horgan $\mathrm{K}$, et al . Cardiovascular events associated with rofecoxib in a colorectal adenoma chemop prevention trial. N Engl J Med 2005; 352: 1092-102.

7 Yang ZF, Shi GZ, Li CZ, Wang HW, Liu K, Liu YM. Electrophysiologic effects of nicorandil on the guinea pig long $\mathrm{QT}_{1}$ syndrome model. J Cardiovasc Electr 2004; 15: 815-20.

8 Lu HL, Li CZ, Liu YM, Weng EQ, Liu B. The effects of Guanxinling on coronary blood flow-contraction force of cardiac muscle and electrical activity of the heart. Chin Heart J 2004; 16: 323-6.

9 Buchanan FG, Holla V, Katkuri S, Matta P, Dubois RN. Targeting cyclooxygenase-2 and the epidermal growth factor receptor for prevention and treatment of intestinal cancer. Cancer Res 2007; 67: 9380-8.

10 Martinez-Gonzalez J, Badimon L. Mechanisms underlying the cardiovascular effects of Cox-inhibition: benefits and risks. Curr Pharm Res 2007; 13: 2215-27

11 Graham DJ, Campen D, Hui R, Spence M, Cheetham C, Levy G, et al. Risk of acute myocardial infarction and sudden cardiac death in patients treated with cyclo-oxygenase 2 selective and non-selective non-steroidal anti-inflammatory drugs: nested casecontrol study. Lancet 2005; 365: 475-81.

12 Mukherjee D, Nissen SE, Topol EJ. Risk of cardiovascular events associated with selective COX-2 inhibitors. JAMA 2001; 286: 954-9.

13 Leroy S, Mosca A, Landre-Peigne C, Cosson MA, Pons G. Ibuprofen in childhood: evidence-based review of efficacy and safety. Arch Pediatr Adolesc Med 2007; 3: 51-8.

14 Huang WF, Hsiao FY, Wen YW, Tsai YW. Cardiovascular events associated with the use of four nonselective NSAIDs (etodolac, nabumetone, ibuprofen, or naproxen) versus a cyclooxygenase-2 inhibitor (celecoxib): a population-based analysis in Taiwanese adults. Clin Ther 2006; 28: 1827-36.

15 Johnsen SP, Larsson H, Tarone RE, McLaughlin JK, Norgard B, Friis $\mathrm{S}$, et al. Risk of hospitalization for myocardial infarction among users of rofecoxib, celecoxib, and other NSAIDs: a population-based case-control study. Arch Intern Med 2005; 165 : 978-84.

16 Liu XK, Tosaki A, Engleman RM, Das DK. Salicylate reduces ventricular dysfunction and arrhythmias during reperfusion in isolated rat hearts. J Cardiovasc Pharm 1992; 19: 209-15.

17 Liu XK, Tosaki, A, Engleman RM, Das DK. Reduction of postischaemic ventricular dysfunction and arrhythmias by trapping hydroxyl radicals with salicylic acid. Int J Tissue React 1993; 15: 25-30.

18 Cheruku KK, Ghani A, Ahmad F, Pappas P, Silverman PR, Zelinger A, et al. Efficacy of nonsteroidal anti-inflammatory medications for prevention of atrial fibrillation following coronary artery bypass graft surgery. Prev Cardiol 2004; 7: 13-8. 